\title{
Application of an analytic hierarchy process to hydrocarbon accumulation coefficient estimation
}

\author{
Gao Yongjin ${ }^{1,2 *}$, Liu Lifeng, ${ }^{1,}$, Liu Huimin ${ }^{2}$, Zheng Feifei ${ }^{1}, W_{\text {u Li }}{ }^{1}$, \\ Zhou Jingjing ${ }^{1}$ and Qu Dongfang ${ }^{1}$ \\ ${ }^{1}$ State Key Laboratory of Petroleum Resources and Prospecting, China University of Petroleum, Beijing 102249, China \\ ${ }^{2}$ Geoscience Research Institute, Shengli Oilfield, SINOPEC, Dongying 257061, China \\ ${ }^{3}$ Laboratory of Integrated Geology and Geophysics Research, China University of Petroleum, Beijing 102249, China \\ (C) China University of Petroleum (Beijing) and Springer-Verlag Berlin Heidelberg 2010
}

\begin{abstract}
The hydrocarbon accumulation coefficient is a key parameter in resources evaluation by genetic techniques. Methods of obtaining its value scientifically have always been an important factor influencing evaluation credibility. In this paper, the hydrocarbon accumulation system is evaluated quantitatively by establishing a hierarchy structure model based on an analytical hierarchy process. The hydrocarbon accumulation system of a higher exploration degree is selected as a calibration area and its hydrocarbon accumulation coefficient can be calculated using methods of hydrocarbon generation potential and reservoir-scale sequence. The hydrocarbon accumulation coefficient of a petroleum accumulation system can be gained by analogy of reservoir forming comprehensive evaluation results with the calibration area. The hydrocarbon accumulation coefficient of each petroleum accumulation system in the upper reservoir-forming combination of the Liaohe Western Sag can be obtained with this method. Practice shows that using the analytical hierarchy process to quantitatively evaluate the hydrocarbon accumulation system and then quantitatively predict the hydrocarbon accumulation coefficient decreases the influence of human factors in resources evaluation, and makes the resources assessment more objective and closer to the actual geological condition.
\end{abstract}

Key words: Hydrocarbon accumulation coefficient, analytical hierarchy process, hydrocarbon resource evaluation, hydrocarbon accumulation system, Liaohe Western Sag

\section{Introduction}

The accumulation coefficient is the ratio of hydrocarbon resource volume to hydrocarbon expulsion volume in a geological unit, and is a key parameter of the genetic method of calculating the resource volume. Hydrocarbon accumulation is a very complex process with a long time and many influencing factors. There are many dissipative processes from oil and gas expulsion from source rocks to the final accumulation, including retention by reservoirs, absorption by surrounding rocks, solution of hydrocarbon in water, filtration diffusion, and tectonic destruction. Therefore, the accumulation coefficient is a reflection of hydrocarbon migration and accumulation processes. It is also a comprehensive reflection of source rocks, migration, reservoir and preservation.

The geological analogy, reservoir-scale sequence, and fuzzy scoring comprehensive evaluation are the current commonly used methods to obtain the hydrocarbon accumulation coefficient. Because the geological factors

*Corresponding author. email: gaoyj123321@sina.com

Received March 31, 2009 which impact hydrocarbon accumulation are complex and have wide ranges, there are many weak points in the above methods. For example, the factors considered are simple, and are affected by humans (Liu et al, 2003; Zhou, 2009). At present, there are a lot of problems to be settled about the mechanism of oil migration and accumulation, so it is very difficult to calculate the accumulation coefficient by simple mathematical simulation (Qiao et al, 2005). Because the geological conditions in different regions vary greatly with considerable uncertainties, even though a quantitative relationship between the accumulation coefficient and the controlling factors of hydrocarbon migration can be set up, it is still hard to guarantee the accuracy of using the relationship in different regions (Zhu et al, 2007; Song et al, 2009). As a result, finding ways to estimate the accumulation coefficient scientifically has always puzzled petroleum geologists.

Many scholars have achieved good results using the analytical hierarchy process (AHP) method in some fields. These include oil and gas exploration area selection (Liu et al, 1996; Guo et al, 2006; Zhou and Hu, 2008), sub-petroleum system evaluation (Jiang et al, 1999), basin exploration program optimization (Zuo et al, 2002), main accumulation controlling factors analysis of lenticular sand bodies (Jiang 
et al, 2003), quantitative evaluation of carbonate reservoirs (Tan et al, 2008), prediction of uranium mineralization (Wang et al, 2009), quantitative evaluation of the formation of hydrocarbon reservoirs (Ma et al, 2006), evaluation of macroscopical preserving conditions for marine strata (Tang et al, 2005), and the quantitative evaluation of the gas accumulation system (Zhu et al, 2005). They all showed that the AHP method is an effective method in the quantitative analysis of a complex system. In this paper, the AHP method is used in the Liaohe Western Sag for quantitative evaluation of the hydrocarbon accumulation system. Based on the establishment of the quantitative evaluation model, selecting the high exploration level area as the calibration area (Hu et al, 2005), combined with the results of the genetic method, the analogy method and the statistical method, using the results of the hydrocarbon generation method and the reservoirscale sequence method, the hydrocarbon accumulation coefficient can be obtained through the reservoir geological analogy between the hydrocarbon accumulation system and the calibration area. Practice has proved that the application of the AHP method provides a scientific basis for the quantitative prediction of the accumulation coefficient. This method can reduce the influence of human factors, and offer a more objective evaluation of resources and a result closer to the geological reality.

\section{AHP method}

\subsection{Basic principle of AHP}

The AHP method was proposed in the United States in the middle of 1970s (Saaty, 1980). It is a method of qualitative and quantitative analysis based on breaking down various elements in the evaluation system into objectives, guidelines, programs and other levels. Firstly, grade the analysis and evaluation system. Secondly, divide the system into different factors according to the properties of the system and the overall goal. Thirdly, based on the interrelationships among the factors, divide the system into combinations of different levels, which constitute a multi-layered structure analysis model. Finally, calculate the relative importance weights of the bottom factors relative to the top factors. The AHP method is effective for quantitative analysis of non-quantitative cases, since it simplifies the analysis and calculation process of the system, models the decision-making process by using less quantitative information, and provides an easy way to solve complex decision-making problems with multi-objective, multi-criteria or non-structural characteristics (Zhao, 1986).

\subsection{Basic steps of AHP}

\subsubsection{Analysis of hierarchical structure}

Based on the structural dependence, a complex system is represented as a multi-level hierarchical structure in order to determine the hierarchical relationships of the relevant elements of decision-making problems. First of all, we analyze the elements and their mutual relations. On the basis of the relationships and the goal to establish a structure, if the relationships among various elements are clear, we can set up the structure directly by experience, or we build an interpretive structural model. The hierarchical structure can generally be divided into target, criterion and project layers.

\subsubsection{Construction of judgment matrix}

We establish a judgment matrix $A$, and accordingly calculate the priority of each element weight. Each element is taken as a judgment criterion for the elements of the next layer. Their degree of importance for the criteria is compared respectively, and then the judgment matrix is established (Table 1). If an element $C_{k}$ plays a dominant role compared with the next level elements $A_{1}, A_{2}, \ldots, A_{n}$, the decisionmakers will make $C_{k}$ as a guideline and compare the relative importance of any two elements $A_{i}$ and $A_{j}$ which are under its control. AHP makes decisions mathematical, greatly simplifies the problem, and makes quantitative analysis of complex issues possible.

Table 1 AHP judgment matrix 1 to 9 scales and their implications

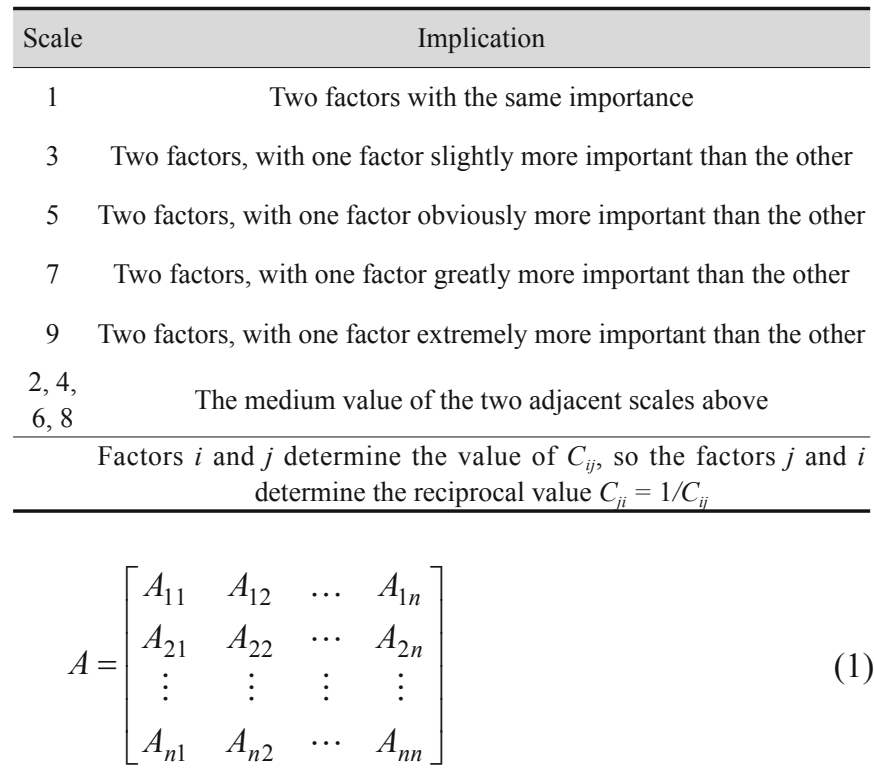

where $A_{i j}$ is the relative weight of pairwise comparison $(i, j=1$, $2, \ldots, n)$.

\subsubsection{Weight calculation}

The basic calculation of AHP is to calculate the largest characteristic root of the matrix and its corresponding eigenvector, and then check the consistency of the judgment matrix.

2.2.3.1 Single hierarchical arrangement calculation

The exact algorithm of the largest eigenvalue and its eigenvector is calculating the characteristic root of the matrix in linear algebra. We can obtain all the eigenvalues, and then find the largest eigenvalue and its corresponding eigenvector. AHP commonly uses the sum and product method (He and Chen, 2002), or the square-root law (Jiang and Li, 2007) to calculate the sorting weight of each element.

The sum and product method makes the elements of matrix $A$ column-normalized, and add by rows. Then the obtained row sum vector is normalized, which is the weights of the corresponding elements $W$. The square-root law makes the elements of matrix $A$ multiplied line by line, and open $n$-th power of the product. Then the square-root vector is 
normalized thus the rank weights $W$ of each corresponding element can be obtained. The maximum eigenvalue of the matrix can be calculated according to the following formula:

$$
\begin{aligned}
& u_{i}=(A * W)_{i} /\left(n * W_{i}\right) \quad(i=1,2, \ldots, n) \\
& \lambda_{\max }=u_{1}+u_{2}+\cdots+u_{n}
\end{aligned}
$$

where, $(A * W)_{i}$ represents the $i$-th element of the matrix $(A * W)$. 2.2.3.2 Consistency test

AHP requires general consistency of the judgment matrix to make the conclusion reasonable. We find a consistency index:

$$
\begin{aligned}
& C I=\left(\lambda_{\max }-n\right) /(n-1) \\
& C R=C I / R I
\end{aligned}
$$

where $R I$ is the average consistency index (Table 2). When $C R<0.10$, we believe that the judgment matrix has satisfactory consistency, otherwise the judgment matrix needs to be adjusted to make it have satisfactory consistency.

Table 2 Average random consistency index of the judgment matrix

\begin{tabular}{c|ccccccccc}
\hline Order number & 1 & 2 & 3 & 4 & 5 & 6 & 7 & 8 & 9 \\
$R I$ & 0.00 & 0.00 & 0.58 & 0.90 & 1.12 & 1.24 & 1.32 & 1.41 & 1.45 \\
\hline
\end{tabular}

\subsubsection{Final hierarchical arrangement}

The final hierarchical arrangement means the final order of all elements, in which the program with greater weight is better. Assuming that the final order weight of all the elements $A_{i}$ of $(k-1)$-th layer is $a_{i}$, and the result of the single hierarchical arrangement of each element $B_{j}$ of the $k$ layers with elements of $A_{i}$ as the criterion is $b_{i j}$ (when there is no connection between $A_{i}$ and $B_{j}, b_{i j}=0$ ), the final weight of elements $B_{j}$ is:

$b_{j}=b_{1 j} * a_{1}+b_{2 j} * a_{2}+\ldots+b_{m j} * a_{m} \quad(j=1,2, \ldots, n)$

where $m$ and $n$ respectively denote the element number of $(k-1)$-th and $k$-th layers.

\subsection{Obtaining the hydrocarbon accumulation coefficient by the AHP method}

Firstly, we select the geological unit with the highest exploration degree as the calibration area, because the understanding of geology and oilfield development are at a high mature stage. The geological resource volume of the area is obtained from the scale sequence method (Yan et al, 2006) and the hydrocarbon expulsion quantity is obtained from the hydrocarbon generation potential method (Zhou and Pang, 2002). The accumulation coefficient is just the ratio of the geological resource volume to the hydrocarbon expulsion quantity in the scale area. The reservoir-scale sequence method is based on the oil and gas reserves that have been discovered. Pareto's Law is used to forecast the not yet discovered reserves and the total amount of the geological resources in the research area. The hydrocarbon generation potential method is based on the concept of the hydrocarbon expulsion threshold, and takes the principle of material balance as its theoretical basis. According to the principle that the quantity of organic matter in the source rocks is the same before and after the hydrocarbon generation process, it is concluded that the burial depth at the turning point of the hydrocarbon generation potential of source rocks can be considered as the hydrocarbon expulsion threshold of the source rock during its evolution, and the hydrocarbon generation potential at this point represents the maximum hydrocarbon generation potential of the source rock. The difference between the maximum value and the current value of the hydrocarbon generation potential represents the hydrocarbon expulsion quantity of the source rock in the geological history. The hydrocarbon expulsion intensity and thickness of the effective source rocks in each buried period, and the hydrocarbon expulsion characteristics can be obtained from the threshold depth and the distribution of the organic matter type in each horizon.

For the low exploration degree area, based on the structure, characteristics and evolution of each subsystem and its elements, we establish the hierarchy structure model of the hydrocarbon accumulation system, obtain the quantitative scores, and calculate the relative weight of the elements according to the established geological evaluation parameter system and the standard values of each hydrocarbon accumulation system. Then, we conduct a comprehensive quantitative evaluation of geological risk in each system through self evaluation and weighting of each element (Table 2), and obtain the accumulation coefficient through comprehensive evaluation analogy of the reservoir forming conditions between the accumulation system and the scale area (Fig. 1, Table 3).

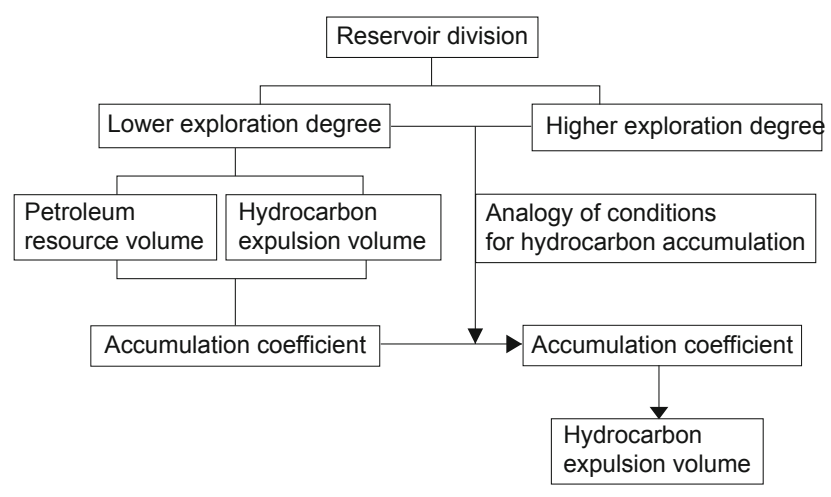

Fig. 1 Procedure of obtaining hydrocarbon accumulation coefficient

The estimation of an accumulation coefficient is based on comprehensive geological evaluation of all related hydrocarbon accumulation systems. The weighted sum of scores of the factors that affect oil and gas accumulation is the comprehensive score. The accumulation coefficient in all hydrocarbon accumulation systems $\left(K_{k}\right)$ can be obtained by multiplying the ratio of the comprehensive score $\left(G_{k}\right)$ in a hydrocarbon accumulation system to that of the calibrated unit $\left(G_{j}\right)$ with the accumulation coefficient of the calibrated unit $\left(K_{j}\right)$. 


$$
\begin{aligned}
G_{k} & =\sum_{i=1}^{n} r_{i} \cdot s_{i} \\
K_{k} & =\frac{G_{k}}{G_{j}} \bullet K_{j} \quad(k=1,2, \ldots, 8)
\end{aligned}
$$

where $K_{k}$ is the accumulation coefficient of a hydrocarbon accumulation system; $K_{j}$ is the accumulation coefficient of the calibrated unit (hydrocarbon accumulation system); $G_{k}$ is the comprehensive geological evaluation index in a hydrocarbon accumulation system; $G_{j}$ is the comprehensive geological evaluation index in the calibrated unit (hydrocarbon accumulation system); $r_{i}$ is the contribution weight of the most primary factor $i$ to subsystem in the $k$-th hydrocarbon accumulation system; $S_{i}$ is the self evaluation score in the $k$-th hydrocarbon accumulation system; $n$ is the number of the most primary factors.

\section{Application example}

The Liaohe Depression is located at the northeast corner of the Bohai Bay Basin in China. It is divided into seven major sub-tectonic units: Shenbei Sag, Damintun Sag, Western Salient, Western Sag, Central Salient, Eastern Sag and Eastern Salient (Zhu, 2000). The Western Sag is the biggest sag in the Liaohe Depression. It is a dustpan-shaped fault sag with an area of $2,530 \mathrm{~km}^{2}$. There are three tectonic belts. These are the western gentle slope zone, the central deep sag and the eastern steep slope zone. The Paleogene Shahejie Formation is the most important hydrocarbon bearing layer, and the Proterozoic and Paleogene Dongying Formation are next. Mesozoic, Paleozoic, and the Neogene Guantao and Minghuazhen formations have the least hydrocarbon. Since the Xing1 Well yielded a high oil flow in 1969, the Liaohe Western Sag has always been the key exploration and development area in the Liaohe Oilfield with more than 2,000 exploration wells, $16 \times 10^{8}$ t proved reserves, and 10 oil and gas fields such as Xintuo, Gaosheng, Shubei, Huanqijin, Xingleng and Shuanghaiyue. It has been divided into two hydrocarbon accumulation combinations, the upper and the lower. In this paper, we discuss the application of the AHP method to obtain the accumulation coefficient in the upper accumulation combination in the Liaohe Western Sag.

\subsection{Hierarchy structure model}

The hierarchy structure model of the hydrocarbon accumulation system is established based on the detailed analysis of geological conditions of the Liaohe Western Sag (Fig. 2). The first layer is the target layer (hydrocarbon accumulation system); the second layer is composed of four subsystems (generation and expulsion hydrocarbon subsystem, reservoir subsystem, migration subsystem and preservation subsystem); the third layer is the static elements and space-time evolution elements within the subsystems (it is the middle layer between the subsystems and the parameters); the fourth layer is composed of 28 elements of the subsystems (the number of elements can increase or decrease according to the degree of exploration and information richness, and the more elements, the higher the level of analysis). The four layers constitute the hierarchy structure through step by step subdivision. The lines in Fig. 2 imply that the lower factors contribute to the upper factors, and all lower factors contribute to the target layer. The different elements of each subsystem stay in different levels, and the space-time location and the evolution process of each subsystem are interrelated, interdependent, mutually influenced, and mutually restricted, showing the connection of various systems. Every subsystem and its elements jointly control the geological conditions of the hydrocarbon accumulation system. The solid line implies affiliation, and the broken line implies the relationship between the spatial location and evolution of the elements and every subsystem.

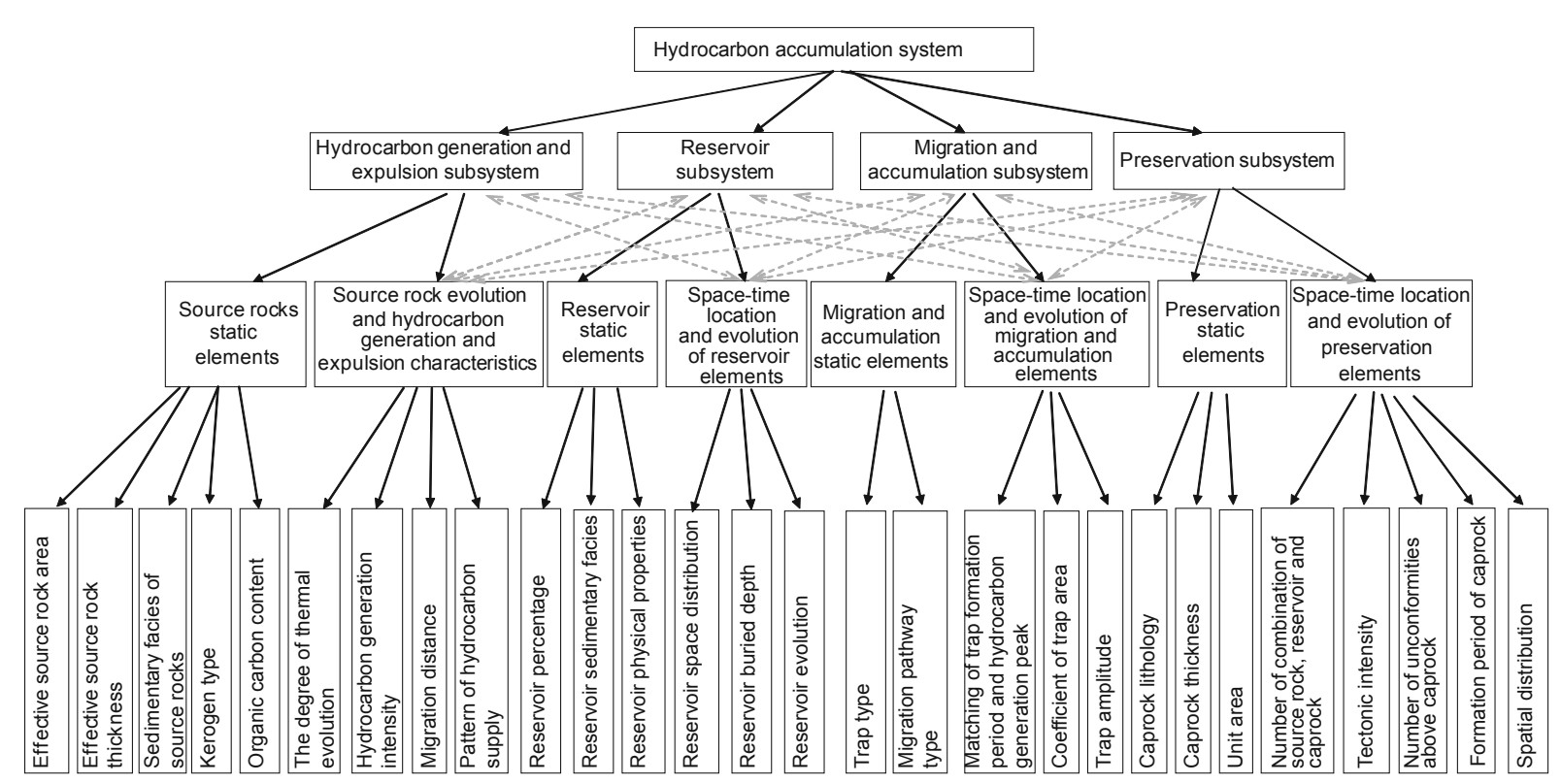

Fig. 2 Comprehensive quantitative evaluation structure of the geological conditions of hydrocarbon accumulation systems by the AHP method 


\subsection{Division of hydrocarbon accumulation system}

According to the geological concept and division principles of the hydrocarbon accumulation system, we first analyze the main migration direction based on the fluid potential field theory. According to the distribution relationship between sand bodies and source kitchen of each layer and oil-source correlation, we put reservoir and its source rocks together. If the fractures serve as a barrier of reservoirs, they are closed in the hydrocarbon accumulation period and can be used as the boundary of accumulation system. If the fractures are open in the hydrocarbon accumulation period, they can not be used as the boundary of accumulation system but can be used as hydrocarbon migration pathways. Therefore, the upper hydrocarbon accumulation combination is divided into six hydrocarbon accumulation systems. They are the Xintuo, Gaosheng, Shubei, Huanqijin, Xingleng and Shuanghaiyue hydrocarbon accumulation systems (Fig. 3).

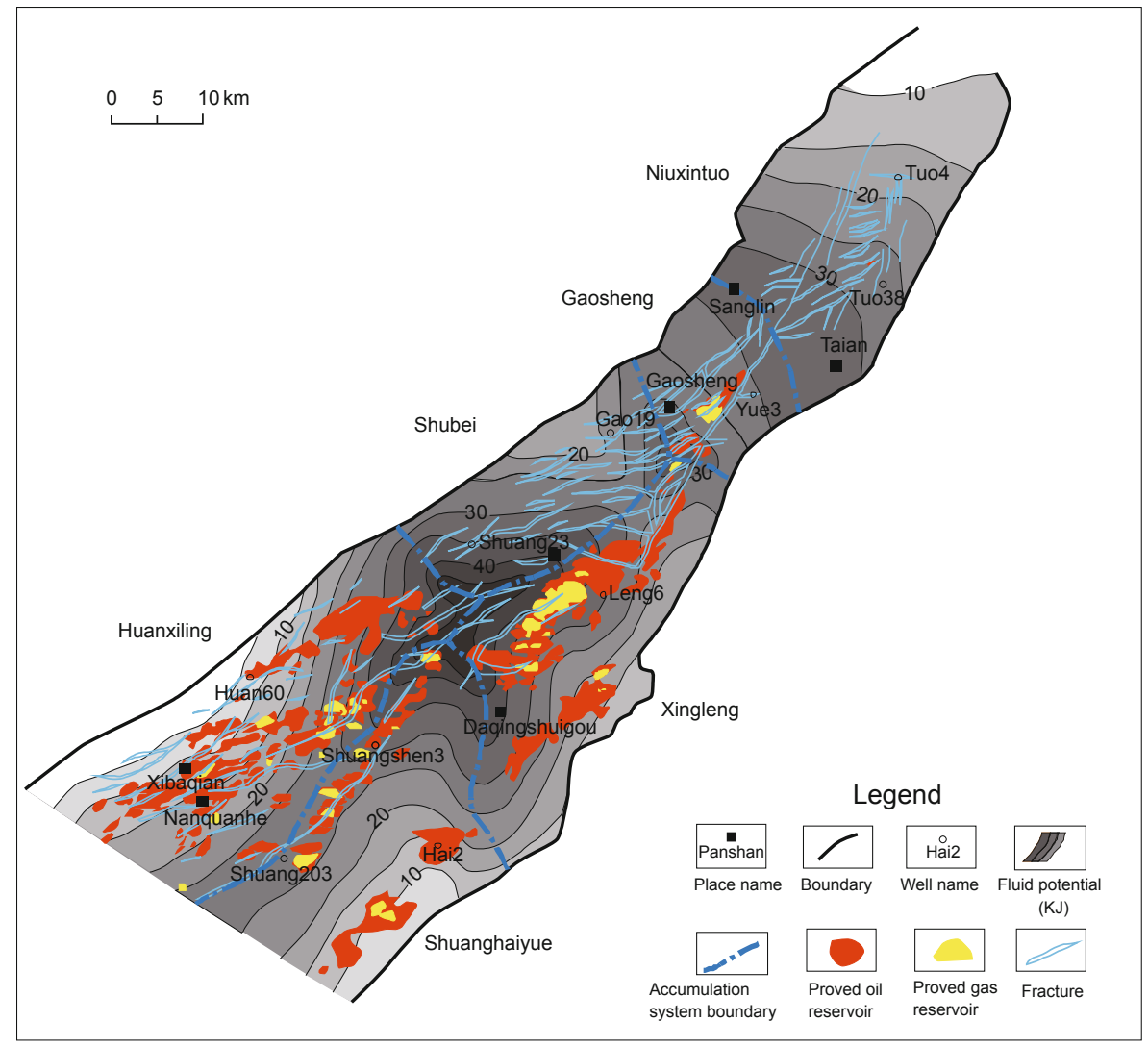

Fig. 3 Division of hydrocarbon accumulation systems in the upper reservoir forming combination in the Liaohe Western Sag

\subsection{Quantitative evaluation of hydrocarbon accumulation system}

Based on a comprehensive analysis of the geological characteristics and reservoir conditions of Liaohe Western $\mathrm{Sag}$, we can set up a hierarchical structure model of the oilgas reservoir formation combination (Fig. 2). According to the characteristics and evolution of hydrocarbon accumulation systems, we compare the elements pairwise, and the judgment matrix of the hydrocarbon accumulation system is established using 1-9 scales (Table 1). Then the mathematical algorithm is used to solve the maximum eigenvalue and its corresponding characteristic vector of the judgment matrix, thus we can obtain the contribution weight of each hydrocarbon accumulation element relative to the hydrocarbon accumulation system. According to the actual geological conditions in the Liaohe Western Sag, we establish a self evaluation standard of each element relative to its own system in the hierarchy model (Table 3 ), and according to the geological conditions of different oil-gas accumulation systems, we mark the geological elements in detail (Table 4). Using the product of the quantitative evaluation score and the corresponding weight of each element, we can get a comprehensive geological quantitative evaluation result for each hydrocarbon accumulation system (Table 5). Whether a hydrocarbon accumulation system contains hydrocarbon or not depends on its own accumulation conditions and the relative weight of every element. Because of the complexity of accumulation, the contributions of the elements of different accumulation systems in different basins to accumulation are different. That a single element has a good advantage does not mean it has more contribution to accumulation. The hydrocarbon-bearing property of the accumulation system is the comprehensive outcome of the conditions, evolution and time-space matching of accumulation elements. 
Table 3 Parameter system and score standard of geological evaluation of hydrocarbon accumulation in the Liaohe Western Sag

\begin{tabular}{|c|c|c|c|c|c|}
\hline & \multirow{2}{*}{ Parameter name } & \multicolumn{4}{|c|}{ Score } \\
\hline & & $0.75-1$ & $0.5-0.75$ & $0.25-0.5$ & $0-0.25$ \\
\hline \multirow{9}{*}{ 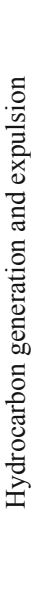 } & Effective source rock area, $\mathrm{km}^{2}$ & $>150$ & $100-150$ & $50-100$ & $<50$ \\
\hline & Effective source rock thickness, $\mathrm{m}$ & $>1500$ & $1000-1500$ & $500-1000$ & $<500$ \\
\hline & Sedimentary facies of source rock & Semi-deep lake and deep lake & Shore-shallow lacustrine & Delta fro & \\
\hline & Kerogen type & I & $\mathrm{II}_{\mathrm{A}}$ & $\mathrm{II}_{\mathrm{B}}$ & III \\
\hline & Organic carbon content, $\%$ & $>3.5$ & $2.5-3.5$ & $1.5-2.5$ & $<1.5$ \\
\hline & Thermal evolution degree, $\%$ & $1.3-2$ & $0.7-1.3$ & $0.5-0.7$ & $<0.5$ \\
\hline & $\begin{array}{l}\text { Hydrocarbon-generating intensity, kt/ } \\
\mathrm{km}^{2}\end{array}$ & $>200$ & $100-200$ & $50-100$ & $<50$ \\
\hline & Migration distance, $\mathrm{km}$ & $<5$ & $5-10$ & $10-20$ & $>20$ \\
\hline & Pattern of supplying hydrocarbon & Convergent flow & Parallel flow & Divergent flow & Linear flow \\
\hline \multirow{6}{*}{ 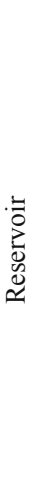 } & Reservoir percentage, $\%$ & $>60$ & $40-60$ & $20-40$ & $<20$ \\
\hline & Reservoir facies & $\begin{array}{l}\text { Delta, coastal beach bar, } \\
\text { reefs, oolitic beach }\end{array}$ & $\begin{array}{c}\text { Fan delta, shore-shallow } \\
\text { lacustrine }\end{array}$ & Neritic shelf, channel & $\begin{array}{l}\text { Pluvial sediments, } \\
\text { alluvial facies }\end{array}$ \\
\hline & $\begin{array}{c}\text { Reservoir physical } \\
\text { properties (porosity }(\%) \text {, } \\
\text { permeability }\left(\times 10^{-3} \mu \mathrm{m}^{2}\right) \text { ) }\end{array}$ & $>30,>1000$ & $20-30,100-1000$ & $10-20,10-100$ & $<10,<10$ \\
\hline & Spatial distribution & Deep depression zone & Slope zone & Slope zone upper end & Others \\
\hline & Buried depth, $m$ & $<1200$ & $1200-2200$ & $2200-3200$ & $>3200$ \\
\hline & Reservoir evolution & Early diagenesis A subage & Early diagenesis B subage & Late diagenesis A subage & $\begin{array}{l}\text { Late diagenesis } \\
\text { B subage }\end{array}$ \\
\hline \multirow{5}{*}{ 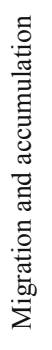 } & Trap type & Anticline & $\begin{array}{l}\text { Faulted anticline, } \\
\text { fault block }\end{array}$ & Stratum & Lithology \\
\hline & Migration pathway type & Reservoir + fault & Reservoir & Fault & Unconformity \\
\hline & $\begin{array}{l}\text { Trap formation period and } \\
\text { hydrocarbon-generating peak }\end{array}$ & Early or at the same time & Lagged behind hydroce & bon-generating peak & $\begin{array}{l}\text { After hydrocarbon } \\
\text { generation finished }\end{array}$ \\
\hline & Trap area coefficient, $\mathrm{km}^{2}$ & $>50$ & $30-50$ & $10-30$ & $<10$ \\
\hline & Trap amplitude, $\mathrm{m}$ & $>500$ & $250-500$ & $100-250$ & $<100$ \\
\hline \multirow{8}{*}{ 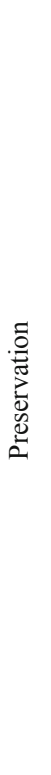 } & Caprock lithology & Evaporite mud-gypsum rock & Thick mudstone & Mudstone & $\begin{array}{l}\text { Brittle mudstone, } \\
\text { sandy mudstone }\end{array}$ \\
\hline & Caprock thickness, $\mathrm{m}$ & $500-1000$ & $300-500$ & $100-300$ & $50-100$ \\
\hline & Unit area, $\mathrm{km}^{2}$ & $<100$ & $100-300$ & $300-500$ & $>500$ \\
\hline & $\begin{array}{c}\text { Number of source-reservoir-cap } \\
\text { assemblages }\end{array}$ & $\begin{array}{c}\text { Wide range of reservoir } \\
\text { development, many sets } \\
\text { of source-reservoir-cap } \\
\text { assemblages }\end{array}$ & $\begin{array}{c}\text { Limited reservoir } \\
\text { distribution, many sets } \\
\text { of source-reservoir-cap } \\
\text { assemblages }\end{array}$ & $\begin{array}{c}\text { Limited reservoir } \\
\text { distribution, few sets } \\
\text { of source-reservoir-cap } \\
\text { assemblages }\end{array}$ & $\begin{array}{c}\text { Reservoir } \\
\text { non-development }\end{array}$ \\
\hline & $\begin{array}{l}\text { Tectonic movement stage } \\
\text { and intensity }\end{array}$ & None & $\begin{array}{l}\text { Low frequency } \\
\text { and low intensity }\end{array}$ & $\begin{array}{l}\text { High frequency and low } \\
\text { intensity, low frequency } \\
\text { and high intensity }\end{array}$ & $\begin{array}{l}\text { High frequency and } \\
\text { high intensity }\end{array}$ \\
\hline & $\begin{array}{c}\text { Number of unconformities } \\
\text { above caprock }\end{array}$ & 0 & $1-2$ & $3-4$ & $\geq 5$ \\
\hline & Formation period of caprock & $\begin{array}{l}\text { Before hydrocarbon } \\
\text { generation or at the same time }\end{array}$ & \multicolumn{2}{|c|}{ Lagged behind hydrocarbon generation } & $\begin{array}{l}\text { After hydrocarbon } \\
\text { generation finished }\end{array}$ \\
\hline & Spatial distribution & Regional seal & Local seal & \multicolumn{2}{|c|}{ Trap caprock } \\
\hline
\end{tabular}


Table 4 Scores of geological conditions of each hydrocarbon accumulation system in the upper petroleum accumulation assemblage of the Liaohe Western Sag

\begin{tabular}{|c|c|c|c|c|c|c|c|}
\hline & \multirow{2}{*}{ Parameter name } & \multicolumn{6}{|c|}{ Score of hydrocarbon accumulation system } \\
\hline & & Niuxintuo & Gaosheng & Shubei & Huanqijin & Xingleng & Shuanghaiyue \\
\hline \multirow{9}{*}{ 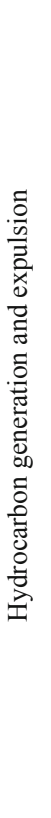 } & Effective source rock area, $\mathrm{km}^{2}$ & 0.258 & 0.056 & 0.144 & 0.388 & 0.403 & 1 \\
\hline & $\begin{array}{l}\text { Effective source rock thickness, } \\
\mathrm{m}\end{array}$ & 0.25 & 0.05 & 0.4 & 0.65 & 1 & 1 \\
\hline & $\begin{array}{l}\text { Sedimentary facies of } \\
\text { source rock }\end{array}$ & $\begin{array}{l}\text { Shore- } \\
\text { shallow } \\
\text { lacustrine }\end{array}$ & $\begin{array}{l}\text { Shore-shallow } \\
\text { lacustrine }\end{array}$ & $\begin{array}{l}\text { Semi-deep lake, } \\
\text { shore-shallow } \\
\text { lacustrine }\end{array}$ & $\begin{array}{l}\text { Shore-shallow } \\
\text { lacustrine, } \\
\text { semi-deep } \\
\text { lake, delta front }\end{array}$ & Semi-deep lake & Semi-deep lake \\
\hline & Kerogen type & $\mathrm{II}_{\mathrm{B}}, \mathrm{III}$ & $\mathrm{II}_{\mathrm{B}}, \mathrm{III}$ & $\mathrm{II}_{\mathrm{A}}, \mathrm{II}_{\mathrm{B}}$ & $\mathrm{I}, \mathrm{II}_{\mathrm{A}}, \mathrm{II}_{\mathrm{B}}$ & $\mathrm{I}, \mathrm{II}_{\mathrm{A}}, \mathrm{II}_{\mathrm{B}}$ & $\mathrm{I}, \mathrm{II}_{\mathrm{A}}, \mathrm{II}_{\mathrm{B}}$ \\
\hline & Organic carbon content, $\%$ & 2.5 & 3.5 & 3.75 & 4.75 & 3.75 & 4.75 \\
\hline & Thermal evolution degree, $\%$ & 0.36 & 0.37 & 0.28 & 0.55 & 0.55 & 0.59 \\
\hline & $\begin{array}{l}\text { Hydrocarbon-generating } \\
\text { intensity, } \mathrm{kt} / \mathrm{km}^{2}\end{array}$ & 5 & 12 & 118.4 & 98 & 118.4 & 101 \\
\hline & Migration distance, $\mathrm{km}$ & $<5$ & 10.92 & 12.47 & 24.65 & 18.32 & $<5$ \\
\hline & $\begin{array}{l}\text { Pattern of supplying } \\
\text { hydrocarbon }\end{array}$ & & Divergent flow & $\begin{array}{l}\text { Parallel flow, } \\
\text { divergent flow, } \\
\text { convergent flow }\end{array}$ & $\begin{array}{l}\text { Parallel flow, } \\
\text { divergent flow }\end{array}$ & $\begin{array}{l}\text { Parallel flow, } \\
\text { divergent flow, } \\
\text { convergent flow }\end{array}$ & $\begin{array}{l}\text { Convergent flow, } \\
\text { divergent flow }\end{array}$ \\
\hline \multirow{6}{*}{ 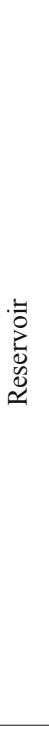 } & Reservoir percentage, \% & $0.45-0.9$ & $0.05-0.9$ & $0.05-0.9$ & $0.1-0.75$ & $0.1-0.8$ & $0.2-0.7$ \\
\hline & Reservoir facies & Fan delta & $\begin{array}{l}\text { Fault trough, } \\
\text { gravity flow } \\
\text { channel, } \\
\text { delta and } \\
\text { fluvial facies }\end{array}$ & $\begin{array}{c}\text { Fan delta, river } \\
\text { channel }\end{array}$ & $\begin{array}{l}\text { Infralittoral, } \\
\text { turbidite, } \\
\text { braided stream } \\
\text { delta, fan delta }\end{array}$ & $\begin{array}{l}\text { Fan delta, } \\
\text { fluxoturbidite } \\
\text { alluvial flat }\end{array}$ & $\begin{array}{l}\text { Fluxoturbidite, } \\
\text { fan delta, } \\
\text { channel }\end{array}$ \\
\hline & $\begin{array}{l}\text { Reservoir physical properties } \\
\text { (porosity }(\%) \text {, permeability } \\
\left.\left(\times 10^{-3} \mu \mathrm{m}^{2}\right)\right)\end{array}$ & $25-29$ & $21-33,600-1800$ & $18-35,0-200$ & $14-33,200-3200$ & $12-36,100-1447$ & $16-30,100-600$ \\
\hline & Spatial distribution & $\begin{array}{l}\text { Slope zone, } \\
\text { deep } \\
\text { depression } \\
\text { zone }\end{array}$ & Upper slope zone & $\begin{array}{l}\text { Slope zone, deep } \\
\text { depression zone }\end{array}$ & Slope zone & $\begin{array}{l}\text { Slope zone, deep } \\
\text { depression zone }\end{array}$ & Deep depression zone \\
\hline & Buried depth, m & & $1450-2310$ & $660-1687$ & $510-3188$ & $580-3519$ & $1400-3525$ \\
\hline & Reservoir evolution & $\begin{array}{l}\text { Early } \\
\text { diagenesis } \\
\text { A subage }\end{array}$ & $\begin{array}{l}\text { Early diagenesis } \\
\text { B subage }\end{array}$ & $\begin{array}{l}\text { Early diagenesis } \\
\text { B subage }\end{array}$ & $\begin{array}{l}\text { Early diagenesis } \\
\text { B subage }\end{array}$ & $\begin{array}{l}\text { Early diagenesis } \\
\text { B subage }\end{array}$ & $\begin{array}{l}\text { Early diagenesis } \\
\text { B subage }\end{array}$ \\
\hline \multirow{5}{*}{ 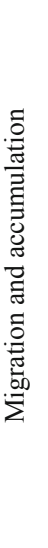 } & Trap type & & $\begin{array}{c}\text { Litho-structural, } \\
\text { structural } \\
\text { lithologic, } \\
\text { lithologic, } \\
\text { fault block, } \\
\text { fault nose }\end{array}$ & $\begin{array}{l}\text { fault nose, } \\
\text { lithologic, } \\
\text { structural } \\
\text { stratigraphic, } \\
\text { structural } \\
\text { lithologic }\end{array}$ & $\begin{array}{c}\text { structural lithologic, } \\
\text { lithostructural, } \\
\text { structural } \\
\text { (fault block) }\end{array}$ & $\begin{array}{c}\text { Anticline, } \\
\text { faulted anticline, } \\
\text { lithologic, } \\
\text { structural lithologic }\end{array}$ & $\begin{array}{l}\text { faulted anticline } \\
\text { and anticline, } \\
\text { structural } \\
\text { lithologic, lithologic }\end{array}$ \\
\hline & Migration pathway type & fault & fault & fault & $\begin{array}{l}\text { Reservoir }+ \text { fault }+ \\
\text { unconformity }\end{array}$ & Fault+reservoir & fault \\
\hline & $\begin{array}{c}\text { Trap formation period and } \\
\text { hydrocarbon generation peak }\end{array}$ & $\begin{array}{l}\text { Early or } \\
\text { same time }\end{array}$ & $\begin{array}{l}\text { Early or same } \\
\text { time }\end{array}$ & $\begin{array}{l}\text { Early or same } \\
\text { time }\end{array}$ & Early or same time & $\begin{array}{l}\text { Early or } \\
\text { same time }\end{array}$ & $\begin{array}{l}\text { Early or } \\
\text { same time }\end{array}$ \\
\hline & Trap area coefficient, $\mathrm{km}^{2}$ & & 0.27 & 0.51 & 0.49 & 0.45 & 0.48 \\
\hline & Trap amplitude, $\mathrm{m}$ & & & 216.67 & 76.81 & 211.41 & 131.25 \\
\hline
\end{tabular}




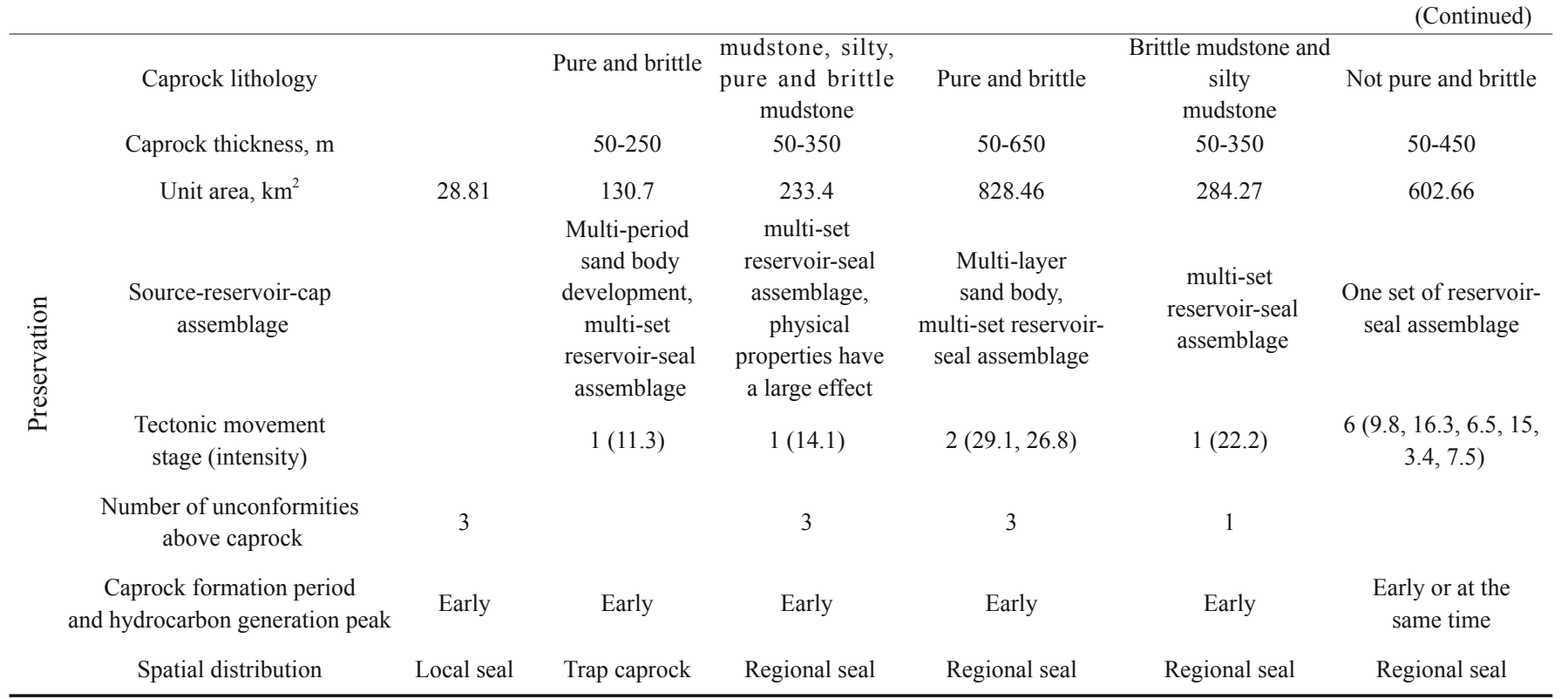

Table 5 Scores and weights of the geological conditions of each hydrocarbon accumulation system in the upper petroleum accumulation assemblage of the Liaohe Western Sag

\begin{tabular}{|c|c|c|c|c|c|c|c|c|}
\hline & \multirow{2}{*}{ Parameter name } & \multicolumn{6}{|c|}{ Score of hydrocarbon accumulation system } & \multirow{2}{*}{ Weight, \% } \\
\hline & & Niuxintuo & Gaosheng & Shubei & Huanqijin & Xingleng & Shuanghaiyue & \\
\hline \multirow{9}{*}{ 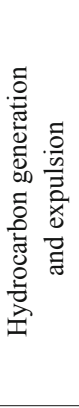 } & Effective source rock area & 0.26 & 0.06 & 0.14 & 0.39 & 0.4 & 1 & 0.59 \\
\hline & Effective source rock thickness & 0.25 & 0.05 & 0.4 & 0.65 & 1 & 1 & 0.72 \\
\hline & Sedimentary facies of source rock & 0.62 & 0.62 & 0.7 & 0.75 & 0.8 & 0.9 & 0.72 \\
\hline & Kerogen type & 0.25 & 0.3 & 0.45 & 0.62 & 0.65 & 0.62 & 0.88 \\
\hline & Organic carbon content & 0.5 & 0.75 & 0.8 & 1 & 0.8 & 1 & 1.07 \\
\hline & Thermal evolution degree & 0.14 & 0.19 & 0.11 & 0.22 & 0.22 & 0.25 & 4.66 \\
\hline & Hydrocarbon-generating intensity & 0.03 & 0.15 & 0.93 & 0.87 & 0.93 & 0.9 & 5.42 \\
\hline & Migration distance & 0.9 & 0.48 & 0.44 & 0.13 & 0.29 & 0.85 & 3.82 \\
\hline & Pattern of supplying hydrocarbon & & 0.4 & 0.68 & 0.63 & 0.68 & 0.77 & 4.01 \\
\hline \multirow{7}{*}{ 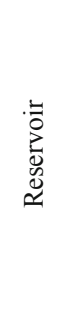 } & Reservoir percentage & 0.84 & 0.56 & 0.53 & 0.45 & 0.51 & 0.49 & 2.38 \\
\hline & Reservoir facies & 0.5 & 0.43 & 0.5 & 0.72 & 0.44 & 0.29 & 2.9 \\
\hline & Reservoir physical properties & 0.68 & 0.7 & 0.69 & 0.55 & 0.66 & 0.53 & 3.55 \\
\hline & (porosity and permeability) & & 0.78 & 0.53 & 0.78 & 0.79 & 0.58 & 3.55 \\
\hline & Spatial distribution & 0.75 & 0.4 & 0.64 & 0.6 & 0.53 & 0.6 & 9.86 \\
\hline & Buried depth & & 0.58 & 0.76 & 0.59 & 0.54 & 0.43 & 8.07 \\
\hline & Reservoir evolution & 0.6 & 0.55 & 0.6 & 0.5 & 0.55 & 0.75 & 8.07 \\
\hline \multirow{5}{*}{ 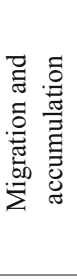 } & Trap type & & 0.6 & 0.4 & 0.45 & 0.65 & 0.7 & 2.19 \\
\hline & Migration pathway type & 0.5 & 0.45 & 0.45 & 0.62 & 0.9 & 0.3 & 2.68 \\
\hline & $\begin{array}{l}\text { Trap formation period and } \\
\text { Hydrocarbon-generating peak }\end{array}$ & & 0.95 & 0.91 & 0.9 & 0.89 & 0.82 & 8.02 \\
\hline & Trap area coefficient & & 0.46 & 0.76 & 0.49 & 0.69 & 0.73 & 6.57 \\
\hline & Trap amplitude & & & 0.44 & 0.19 & 0.44 & 0.3 & 4.54 \\
\hline \multirow{8}{*}{ 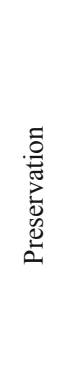 } & Caprock lithology & & 0.3 & 0.23 & 0.3 & 0.25 & 0.2 & 0.92 \\
\hline & Caprock thickness & & 0.33 & 0.36 & 0.46 & 0.38 & 0.47 & 0.98 \\
\hline & Unit area & 0.93 & 0.71 & 0.58 & 0.09 & 0.52 & 0.2 & 0.86 \\
\hline & Source-reservoir-cap number & & 0.6 & 0.5 & 0.9 & 0.6 & 0.25 & 3.51 \\
\hline & $\begin{array}{c}\text { Tectonic movement stage } \\
\text { and intensity }\end{array}$ & & 0.7 & 0.66 & 0.4 & 0.5 & 0.45 & 2.87 \\
\hline & $\begin{array}{l}\text { Number of unconformities } \\
\text { above caprock }\end{array}$ & 0.45 & & 0.45 & 0.45 & 0.7 & & 2.87 \\
\hline & Caprock formation period & 0.9 & 0.9 & 0.9 & 0.9 & 0.9 & 0.85 & 2.35 \\
\hline & Spatial distribution & 0.65 & 0.4 & 0.75 & 0.8 & 0.75 & 0.9 & 2.87 \\
\hline
\end{tabular}


According to Table 3, the main factors influencing the accumulation geological conditions of every system are the spatial distribution of reservoir, reservoir evolution, matching relationship of trap formation period and hydrocarbon generation peak, reservoir depth, trap area coefficient, hydrocarbon-generating intensity of source rock, thermal evolution extent of source rock, and trap amplitude (importance order). The total weight of the eight factors surpasses $50 \%$.

\subsection{Estimation of the hydrocarbon accumulation coefficient of the upper reservoir-forming combination in the Liaohe Western Sag}

By analyzing the regions whose geological conditions and resource potential are understood clearly, the anatomy for the calibrated unit is aimed at concluding the relationship between geological conditions and resource potential and setting up a parameter link so that an accurate basis can be provided for an analogy of resource potential. In order to recognize geological conditions and resource potential correctly and objectively, the calibrated unit is selected according to the "three-high" principles (Hu et al, 2005). They are (1) higher exploration degree; (2) higher understanding of the geological conditions; (3) higher proved reserves ratio. After comprehensive analysis of the Liaohe Western Sag, the Xingleng hydrocarbon accumulation system was selected to be the calibrated unit in the upper reservoirforming combination.

The geological resources are calculated by the reservoirscale sequence method. As a result, the proved reserves of the Xingleng accumulation system is $6.72 \times 10^{8} \mathrm{t}$, and the hydrocarbon expulsion quantity of the system according to the hydrocarbon generation potential method is $19.71 \times 10^{8} \mathrm{t}$. So its accumulation coefficient is $34.1 \%$. Finally, we can obtain the accumulation coefficient (Table 6) of every accumulation system of the upper reservoir-forming combination in the Liaohe Western Sag according to Eqs. (2) and (3).

Table 6 Hydrocarbon accumulation coefficient of each hydrocarbon accumulation system in the upper reservoir-forming combination of the Liaohe Western Sag

\begin{tabular}{ccc}
\hline Hydrocarbon accumulation system & Geological comprehensive evaluation coefficient & Accumulation coefficient \\
Gaosheng & 0.485 & 0.266 \\
Huanqijin & 0.581 & 0.319 \\
Niuxintuo & 0.385 & 0.212 \\
Shubei & 0.619 & 0.340 \\
Shuanghaiyue & 0.593 & 0.326 \\
Xingleng (calibrated unit) & 0.621 & 0.341 \\
\hline
\end{tabular}

\section{Conclusions}

1) There are many geological factors that affect hydrocarbon migration and accumulation. They are interrelated, interdependent, mutually affected and mutually restricted and their hierarchical structure characteristics are clear. An analytical hierarchy process can effectively reflect the internal relationships among geological factors. Every hydrocarbon accumulation system can be evaluated quantitatively and the accumulation coefficient can also be predicted quantitatively combined with quantitative evaluation results in the calibrated unit.

2) The quantitative accumulation coefficient prediction for the hydrocarbon accumulation system in the upper reservoir-forming combination in the Liaohe Western Sag indicated that the hydrocarbon accumulation coefficient can be estimated quantitatively by an analytical hierarchy process which is made more objective and practical by decreasing subjective factors.

3) Because of the complexity of hydrocarbon generation, migration and accumulation mechanisms and the uncertainty of geological factors, four points should be noticed when calculating hydrocarbon accumulation coefficient by AHP. (a) Mastering the geological characteristics of the study area and dividing hydrocarbon accumulation systems correctly; (b) Grasping sensitive parameters that affect hydrocarbon generation, migration and accumulation in the study area so that the comprehensive quantitative evaluation structure for hydrocarbon accumulation system by analytical hierarchy process can be set up correctly; (c) Establishing a value standard that is in accordance with actual geological conditions in the study area; (d) Setting up an evaluation matrix for hydrocarbon accumulation systems, which is also in accordance with actual geological conditions so that the relative weights of all accumulation factors could be obtained.

\section{Acknowledgements}

This study was supported by the Foundation Project of State Key Laboratory of Petroleum Resources and Prospecting (PRPDX2008-05) and the "973" National Key Basic Research Program (2006CB202308). 


\section{References}

Guo M, Zhu J W, Gong Q H, et al. Application of an analytical hierarchy process for hydrocarbon resource evaluation of faulted depressions - an example from the southeast uplift in the Songliao Basin. Global Geology. 2006. 25(1): 54-58 (in Chinese)

$\mathrm{He} \mathrm{B}$ and Chen $\mathrm{C}$. Theoretic proof of priority result about ANC in analytic hierarchy process. Journal of Yunnan Normal University. 2002. 22(4): 11-14 (in Chinese)

Hu S Y, Tian K Q, Liu G D, et al. Calibration area analytical method and key parameters of hydrocarbon resource evaluation. Acta Petrolei Sinica. 2005. 26(supplement): 49-54 (in Chinese)

Jiang G R and Li Y. Application of the AHP method in determining the evaluation index weights of knowledge management in consulting firms. Science \& Technology Progress and Policy. 2007. 24(7): 172174 (in Chinese)

Jiang Z X, Chen D X, Qiu G Q, et al. AHP applied in the research of main controlling factors for studying formation of sand lens reservoir. Petroleum Exploration and Development. 2003. 30(3): 44-48 (in Chinese)

Jiang Z X, Liu H F, Huang Z L, et al. Division and evaluation of petroleum sub-systems in the Tuha Basin. Journal of Daqing Petroleum Institute. 1999. 23(4): 1-5 (in Chinese)

Liu G D, Zhao W Z, Hu S Y, et al. Prediction models of migration and accumulation coefficient for petroleum migration and accumulation units. Petroleum Exploration and Development. 2003. 30(5): 53-55 (in Chinese)

Liu M, Liu Y and Chen Q L. AHP applied in petroleum exploration and selected-area evaluation of the Tarim Basin. Petroleum Geology \& Experiment. 1996. 18(4): 420-426 (in Chinese)

Ma H, Liu G D, Zhu L L, et al. Application of the analytical method for gradual layers to the quantitative evaluation of the formation of hydrocarbon reservoirs - take the Yancheng Depression as example. Journal of Daqing Petroleum Institute. 2006. 30(6): 1-4 (in Chinese)

Qiao Y F, Mao X P and Xin G Z. Quantitative simulation of hydrocarbon migration. Earth Science-Journal of China University of Geosciences. 2005. 30(5): 617-622 (in Chinese)

Saaty T L. The Analytic Hierarchy Process. New York: McGraw Hill. 1980: 50-52

Song N, Chen L Q and Dai Z P. Determining the petroleum accumulation coefficient in Subei Basin. Journal of Oil and Gas Technology. 2009. 31(3): 207-209 (in Chinese)

Tan X C, Ding X, Chen J S, et al. Application of hierarchic analysis to quantitative evaluation of carbonate reservoir. Journal of Southwest Petroleum University (Science \& Technology Edition). 2008. 30(2): 38-40 (in Chinese)

Tang J G, Mei L F, Shen C B, et al. Evaluation of macroscopical preserving conditions for the marine strata of Yunnan-GuizhouGuangxi region. Geological Science and Technology Information. 2005. 24(2): 7-11 (in Chinese)

Wang Y J, Li M S, Ma M T, et al. Application of an analytic hierarchy process for uranium deposit prediction in the north Tarim Basin. Geological Science and Technology Information. 2009. 28(4): 7182 (in Chinese)

Yan K, Xu S Y, Cai C Q, et al. Application of the reservoir trap size sequence method to resource assessment of the Shengtuo area. Geological Journal of China Universities. 2006. 12(1): 142-146 (in Chinese)

Zhao H C. Analytic Hierarchy Process. Beijing: Science Press. 1986. 3044 (in Chinese)

Zhou J and Pang X Q. A method for calculating the quantity of hydrocarbon generation and expulsion. Petroleum Exploration and Development. 2002. 29(1): 24-28 (in Chinese)

Zhou T Q and Hu J W. Evaluation of oil-gas geological anomalies based on hierarchical analysis for the Chuxiong Basin, Yunnan Province. Geological Journal of China Universities. 2008. 14(2): 237-242 (in Chinese)

Zhou Z Y. Establishment of a statistical model for oil migration and accumulation coefficients in rift basins in East China. Xinjiang Petroleum Geology. 2009. 30(1): 9-12 (in Chinese)

Zhu F B. Research into organic maturation and petroleum generation in the Western Depression, Liaohe Basin. Geological Science and Technology Information. 2000. 19(3): 53-56 (in Chinese)

Zhu H Q, Pang X Q, Jiang Z X, et al. Studying methods and application of the hydrocarbon accumulation coefficient. Earth ScienceJournal of China University of Geosciences. 2007. 32(2): 260-265 (in Chinese)

Zhu Z Y, Pei J Y, Liu H, et al. Quantitative evaluation of the gas reservoir formation system of Jurassic-Tertiary in the Kuche Depression. Petroleum Geology \& Oilfield Development in Daqing. 2005. 24(1): 27-30 (in Chinese)

Zuo Y D, Xu G S and Liu S G. The application of an analytical hierarchy process to selecting the basin exploration projects. Journal of Chengdu University of Technology (Science \& Technology Edition). 2002. 29(3): 305-309 (in Chinese)

(Edited by Hao Jie) 